\title{
ENTREPRENEURSHIP IMPLEMENTATION STRATEGIES AND UNIVERSITY STUDENTS' JOB CREATION PLANS IN RIVERS STATE, NIGERIA
}

\author{
Nwabueze, Ifeanyichukwu Emmanueli, \\ Anyanwu, Jerome \\ Department of Educational Management, \\ Faculty of Education, \\ University of Port Harcourt, \\ Nigeria
}

\begin{abstract}
:
This study examined entrepreneurship implementation strategies and university students' job creation plans in Rivers State. Two research questions and two corresponding null hypotheses guided the study. The theoretical position was anchored on the: Structural Functional" theory propounded by Gabriel Almond in (1965). This study adopted a descriptive survey design with a population of all the (3) three universities in Rivers State. A stratified random sampling technique was used to draw a sample size of 259 university lecturers representing $10 \%$ of the entire population. A 27 items self-designed questionnaire tagged: Entrepreneurship Implementation Strategies and University Students' Job Creation Plans Questionnaire (EISUSJCPQ)" was used for data collection. Test-retest technique was used to determine the reliability of the instrument which yielded a coefficient index of 0.84 using Pearson Product Moment Correlation Coefficient ( $\mathrm{r}$ ) which is high, reliable and adequate for the study. The findings revealed inter alia: Provision of practical skills for job creation, provision of functional knowledge for self-reliance, training of university students for job creation plans and engaging university students for research work are the ways functional curriculum and entrepreneurship programme centres implementation strategies enhance university students job creation plans in Rivers State. Based on the findings, it was recommended that government and other stakeholders in education should establish entrepreneurial programme centres where students should exhibit financial skills, business skills, public relations skills and competencies to start a business.
\end{abstract}

Keywords: entrepreneurship, implementation strategies, university students, job creation plan

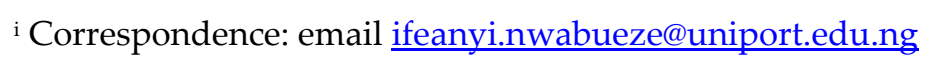




\section{Introduction}

It is a common experience that about $80 \%$ of the graduates from Nigerian universities generally and Rivers State in particular find it very difficult to get employment every year. This is particularly due to the curricula of the universities and other tertiary institutions, which lay emphasis on training for white collar jobs (Amuseghan \& Tayo, 2009). Entrepreneurship has become a buzzword that has gained a lot currency in the social and economic world at both national and global levels hence the importance of entrepreneurship curriculum. A study by Iqbal, Melhen and Kokash (2012) showed that the world has become global, uncertain and complex and hence required diversified entrepreneurial knowledge and skills to respond to the twin challenges of shrinking economies and unemployment.

The importance of entrepreneurship implementation strategies, knowledge and skills in graduates as echoed by Teshome (2014) who argued that modem day universities are now under pressure to produce graduates with the ability to take advantage of opportunities and come up with their own job creation plans as a means of mediating the challenge of unemployment. According to Munyanyiwa (2015), the global economic crises as well as domestic political and economic developments have resulted in low levels of industrialization and high employment hence the need for entrepreneurship education in universities which traditionally churned out graduates for the job market rather than for employment creation. The above is also supported by Basu and Virick (2008) who argued that due to the now perceived critical importance of entrepreneurship in curbing unemployment and most importantly in the socio-economic development of nations, universities are now tasked with the unenviable responsibility of introducing entrepreneurship curricula as a mitigating measure.

Entrepreneurship in the narrowest sense, involved capturing ideas, converting them into products and, or services and then building a venture to take the product to market (Johnson, 2011). In the same vein, entrepreneurship is an undertaking in which one is involved in the task of creating and managing an enterprise for purpose (Olagun, 2014). It is equally the process of identifying opportunities in the marketplace, marshaling the resources required to pursue these opportunities and investing the resources to exploit the opportunities for long term gains (Mbah, 2008). Therefore Gerba (2012) defined entrepreneurship education as a means of developing entrepreneurial skills in people which skills manifest through creative strategies, innovative tactics, uncanny identification of trends and opportunities in the market.

Strategy according to Jeong (2013) is a predetermined comprehensive course of action which can be taken in order to attain a specific goal or aim. A strategy is therefore a well-designed action which has been identified and developed as most effective in reducing a phenomenon. According to Lombard (2011) strategy is an action which involved two or more individuals coordinating, planning, implementing and evaluating an activity in pursuit of a goal. On the other hand, entrepreneurship implementation in universities includes among others: establishment of functional entrepreneurial 
curriculum in line with market demand and designing of entrepreneurship programme centres in institutions.

The importance of functional curriculum as a strategy for entrepreneurship implementation cannot be over-emphasized. Functional curriculum is one that is designed to teach students skills, through formal interaction to equip them to function as competent and accepted adults in the society. Entrepreneurship curriculum has the mandate to equip the youth with functional knowledge and skill to build up their character, attitude and vision. It has vital role in developing eco-system that promotes innovation (European Union, 2006). QAA (2012) remarked its importance for providing the base for innovation and creating a value system; and developing entrepreneurial culture, which drives wealth creation and gives further push to innovations.

Functional curriculum is one that is designed to teach students skills, through formal interaction to equip them to function as competent and accepted adults in the society. Entrepreneurship curriculum has the mandate to equip the youth with functional knowledge and skill to build up their character, attitude and vision. European Union (2006) asserted that functional curriculum as a strategy of entrepreneurship implementation has a vital role in developing eco-system that promotes innovation. QAA (2012) in his own view, remarked the importance of functional curriculum for providing the base for innovation.

Abraham (2001) asserted that functional curriculum/education is the curriculum that equips recipients with adequate knowledge, skills, and competences to compete effectively for job placements within their environment. Functional education according to Abraham (2011) is in the simplest sense, a fit - for purpose education. It is the type of education given to suit the needs of the recipients to meet the demands of, and function effectively within his environment, proving useful to the recipient in his peculiar circumstances. Accordingly, Farhangmerh, Goncalves and Sarmento (2016) did an empirical work to see if there is a correlation between entrepreneurship education and entrepreneurial motivation among university students. The two findings were:

- Entrepreneurship competencies are predictions of entrepreneurship motivation while knowledge base is not;

- Entrepreneurship education does not improve the motivation of university students to become entrepreneurs.

The study submitted that to increase entrepreneurship motivation, pedagogy should emphasize the development of student entrepreneurship skills. These negative findings need not dissuade us from pushing forward with entrepreneurship education as a basis for development of strong, well-motivated, and successful entrepreneurs. We need to be reminded that the European Commission has established that at least $20 \%$ of college students that were involved in on-the-job exposure in industries went into private business after leaving school.

In order, therefore, to build a strong entrepreneurship foundation in graduates, Henry, Hull, and Leitch (2003) argued that when developing or reviewing the entrepreneurship curriculum, courses such as the development of new organizations, 
new markets, and new products must form the basis of an entrepreneurship curriculum whilst business management courses must emphasize the knowledge and skills required for business practice. For such a curriculum to be effectively developed or reviewed, Mynanyiwa and Mutsau (2010) argued that four perspectives need to be taken into consideration namely: (a) the programme can be developed or reviewed from the perspective of the educators (lecturers) where curriculum is defined based on the expertise of the educators, (b) It can also be developed based on the need of students, (c) the entrepreneurship curriculum can be analyzed from the point of view of those who designed it, and (d) evaluators and reviewers of the curriculum can influence the curriculum by making judgements on the curriculum content based on the pre-set criteria of programme quality and effectiveness.

One of such strategies for achieving this in Rivers State is teaching and research at entrepreneurship and innovation centres by universities and other tertiary institutions and the promotion of universities - private sector collaboration. This will involve developing the capacity of staff and students in entrepreneurship and innovation, engaging in outreach activities with small and medium enterprises through such interventions as business incubators. Training of entrepreneurs and conducting researches and consultancies by small business development centres in universities are considered inevitable for patenting entrepreneurial, industrial and economic growth in Rivers State. This is the approach being adopted by National Universities Commission (NUC) through its directive to all universities in Nigeria for establishment of the centres for entrepreneurship and linkage programmes (European Commission, 2006).

Entrepreneurship programme centres are private sector development units designed to assist Nigerian students to start new business, expand and diversify existing ones. Assistance is provided in the areas of entrepreneurship training, business consulting, extension services, research, information gathering and dissemination, production processes, loan packaging etc. The centre facilitates the implementation of the entrepreneurship education in the curricular of All National diploma (ND) and High National Diploma (HND) programmes in the college. The centre is also involved in research, consultancy, programme development and skills acqusitions for prospective entrepreneurs.

Another entrepreneurship implementation strategy has to do with designing of entrepreneurship programnme centres in institutions. Entrepreneurship programme centres are private sector development units designed to assist Nigerians to start new business, expand and diversify existing ones. Assistance is provided in the areas of entrepreneurship training, business consulting, extension services, research, information gathering and dissemination, production processes, loan packaging, etc. The centre facilitates the implementation of the entrepreneurship education in the curricula of All National Diploma (ND) and Higher National Diploma (HND) programmes in the college. The centre is also involved in research, consultancy, programme development and skills acquisitions for prospective entrepreneurs (Centre for Entrepreneurship Development, 2018). 
To sum up, entrepreneurship education has the potential to enable youths to gain skills and create their own job, hence the study investigated implementation strategies and university students job creation plans in Rivers State.

The theoretical framework of this study is anchored on the "Structural Functional Theory" as developed by Gabriel Almond in (1965). Structural - functional approach is a framework for building the theory that sees society as a complex system whose parts work together to promote solidarity and stability. This approach focuses on the importance of social structure, a relatively stable pattern of social behaviour.

Structural functional theory is based on assessing (individually and collectively) the support/components or framework on which a system depends. Structural functionalism ensures that the process of identifying lacunas in a system bears directly on the impact in the functioning of the system. A basic assumption of the theory is that the unit of analysis is a system with clear structural delineation for the various components that are interrelated and inter-dependent. The goal seeking component entrepreneurship education means that the curriculum should be as functional as far as possible. Functional curriculum is one that is designed to teach students skills, through formal interaction to equip them to function as competent and accepted adults in the society. Functionally, entrepreneurship education is a training that stimulates in the students the urge to better their lives; by generating value through the creation or expansion of economic activities and the identification and exploitation of new products, processes or markets. This functional analysis of the system hinges on the submission of consortium for Entrepreneurship Education (2012) that Entrepreneurship Education should be differentiated from a textbook focused course.

The implementation implication being that the entrepreneur is a risk taker. The propensity to take risks is reinforced through training and understanding of the business train. To inculcate the requisite training and confidences to be successful entrepreneurs, there is the need to optimize both the internal and external conditions that stand as limitation. Entrepreneurship education as a practical oriented venture, with lifelong impact on individuals and the society as a whole, needs to be adequately focused; taking into consideration the needed support structure for impact. Based on the explanations above, this theory is suitable for this study since it assumed that the goal seeking component of entrepreneurship education means that the curriculum should be functional as far as possible.

\section{Statement of the Problem}

It is a common experience that about $80 \%$ of the graduates from Nigerian universities generally and Rivers State in particular find it very difficult to get employment every year. An ads for an opening attracts 5,000 employment applications! This is partly due to the curriculum of the universities and other tertiary institutions, which lay emphasis on training for white collar jobs. For example, current national and regional policy thrusts like National Economic Empowerment and Development Strategy (NEEDS) and the New 
Partnership for Africa's Development (NEPAD) have been sensitizing the youths by emphasizing on poverty eradication, employment generation and wealth creation as well as public - private partnership. Also, a number of initiatives like the National Poverty Eradication Programme (NAPEP) and the establishment of Small and Medium Enterprises Development Agency of Nigeria (SMEDAN) have been introduced.

However, from what the researcher has observed as an educational stakeholder, the situation remained the same or unchanged. To them, one of the possible causes is that this initiative in Nigeria addressed only the output end of capacity development solving problem. In addressing the input end, therefore, a complementary approach is required. Besides, even the educational system that addressed the output end either lays more emphasis on content and knowledge acquisition for its sake or just stressed the inquiry discovery model of teaching and learning.

It is against this backdrop that the study examined entrepreneurship implementation strategies and university students' job creation plans in Rivers State. The elements of the problem focused on the ways functional curriculum establishment and entrepreneurship development programme centre strategies enhance university students' job creation plans in Rivers State.

\subsection{Aim and Objectives of the Study}

The aim of the study generally is to examine entrepreneurship implementation strategies and university students' job creation plans in Rivers State, Nigeria. Specifically, the objectives were to:

- find out the ways functional curriculum implementation strategy enhances university students' job creation plans in Rivers State.

- determine the ways entrepreneurship programme centre implementation strategy enhances university students job creation plans in Rivers State.

\subsection{Research Questions}

The study is guided by the following research questions.

- How does functional curriculum implementation strategy enhance university students job creation plans in Rivers State?

- In what ways does entrepreneurship programme centre implementation strategy enhance university students' job creation plans in Rivers State?

\subsection{Hypotheses}

The study was anchored on the following hypotheses.

$\mathbf{H}_{\mathrm{ol}}$ : There is no significant difference between the mean scores of male and female lecturers on the ways functional curriculum implementation strategy enhances university students' job creation plans in Rivers State.

$\mathbf{H}_{\mathbf{o} 2}$ : There is no significant difference between the mean scores of male and female lecturers on the ways entrepreneurship programme centre implementation strategy enhances university students' job creation plans in Rivers State. 


\section{Methodology}

This study adopted a descriptive survey design. The population of the study comprised the (3) three universities in Rivers State. A stratified random sampling technique was used for this study. A sample size for this study was two hundred and fifty-nine (259) representing $10 \%$ of the entire population of academic staff of the public universities. Kpee (2015) considered such percentage appropriate to serve as an acceptable sample for a population running into thousands; the sample size comprised 163 male and 96 female lecturers drawn using the proportionate stratified random sampling technique. This ensured that all members of the population are given equal opportunity of being selected. The instrument used for data collection was 10 items questionnaire tagged: "Entrepreneurship Implementation Strategies and University Students' Job Creation Plans Questionnaire (EISUSJCPQ)".

The instrument was validated by experts in the field of Educational Management and Measurement and Evaluation of the University of Port Harcourt. Test-retest technique was used to determine the reliability of the study using data from the pilot study carried out on 20 participants outside the sample size. A reliability index of 0.84 was established using Pearson Product Moment Correlation Coefficient which is high, reliable and adequate for the study. The instrument was administered personally by the researcher and all the copies distributed were retrieved without loss. Research questions were analyzed using tables, mean and standard deviation and the mean scores 2.50 and above were seen as agreed while below 2.50 were seen as disagreed. The null hypotheses formulated were tested using z-test at 0.05 level of significance. The weighted mean scores as follows: Strongly Agreed $(\mathrm{SA})=4$ points; Agreed $(\mathrm{A})=3$ points; Disagree $(\mathrm{D})=$ 2 points; Strongly Disagree $(\mathrm{SD})=1$ point.

Thus, $4+3+2+1=10 / 4=2.50$.

\section{Result of Data Analysis}

Research Question 1: How does functional curriculum implementation strategy enhances university students' job creation plans in Rivers State?

Data on Table 4.1 showed that items $(1-4)$ had weighted mean scores above the criterion mean of 2.50 and were adjudged as the ways functional curriculum implementation strategy enhances university students' job creation plans in Rivers State. 
Table 4.1: Weighted mean, standard deviation and rank orders statistics of male and female lecturers on the ways functional curriculum implementation strategy enhances university students' job creation plan in Rivers State

\begin{tabular}{|c|c|c|c|c|c|c|c|c|}
\hline \multirow{3}{*}{ S/No } & \multirow{3}{*}{ Items } & \multicolumn{2}{|c|}{$n=163$} & \multicolumn{2}{|c|}{$\mathrm{n}=96$} & \multirow{3}{*}{$\begin{array}{c}\text { Mean } \\
\text { set }\end{array}$} & \multirow{3}{*}{$\begin{array}{l}\text { Rank } \\
\text { order }\end{array}$} & \multirow{3}{*}{ Remark } \\
\hline & & \multirow{2}{*}{$\begin{array}{c}\begin{array}{c}\text { Male } \\
\text { teachers }\end{array} \\
\bar{x}_{1} \\
\end{array}$} & \multirow[t]{2}{*}{$\mathrm{SD}_{1}$} & $\begin{array}{l}\text { Female } \\
\text { lecturers }\end{array}$ & \multirow[t]{2}{*}{$\mathrm{SD}_{2}$} & & & \\
\hline & & & & $\bar{x}_{2}$ & & & & \\
\hline 1. & $\begin{array}{l}\text { Provision of practical } \\
\text { skills for job creation }\end{array}$ & 2.70 & 1.13 & 2.71 & 1.14 & 2.71 & $2^{\text {nd }}$ & Agreed \\
\hline 2. & $\begin{array}{l}\text { Provision of functional } \\
\text { knowledge for } \\
\text { self-reliance }\end{array}$ & 2.83 & 0.92 & 2.80 & 0.87 & 2.82 & $1^{\text {st }}$ & Agreed \\
\hline 3. & $\begin{array}{l}\text { Development of } \\
\text { eco-system that } \\
\text { promotes innovation }\end{array}$ & 2.75 & 1.27 & 2.55 & 1.27 & 2.65 & $3^{\text {rd }}$ & Agreed \\
\hline 4. & $\begin{array}{l}\text { Inoculating the spirit of } \\
\text { entrepreneurial culture }\end{array}$ & 2.64 & 1.05 & 2.61 & 1.05 & 2.63 & $4^{\text {th }}$ & Agreed \\
\hline 5. & $\begin{array}{l}\text { Identification of } \\
\text { business opportunities }\end{array}$ & 2.40 & 0.96 & 2.42 & 0.93 & 2.41 & $5^{\text {th }}$ & Disagreed \\
\hline & Grand moan & 13.32 & 5.33 & 13.09 & 5.26 & 13.21 & & \\
\hline & Grand mean & 2.66 & 1.07 & 2.62 & 1.05 & 2.64 & & \\
\hline
\end{tabular}

Source: Survey Data (2020).

Legend

\begin{tabular}{|l|l|}
\hline $\bar{x}_{1}-$ Mean of Male Lecturers & Scale \\
\hline $\mathrm{D}_{1}=$ Standard Deviation 1 & $1.00-2.49$ Disagree \\
\hline $\bar{x}_{2}=$ Mean of Female lecturers & $2.50-4.00$ Agree \\
\hline $\mathrm{D}_{2}=$ Standard Deviation 2 & \\
\hline $\bar{x} \bar{x}=$ Weighted Mean & \\
\hline
\end{tabular}

While item 5 was rejected because it had mean score that is lower than the criterion mean of 2.50 In summary, with an aggregate weighted mean of 2.64 which is above the criterion mean of 2.50 the respondents agreed that the ways functional curriculum implementation strategy enhances university students job creation plans in Rivers State include: provision of practical skills for job creation, provision of functional knowledge for self-reliance, development of ecosystem that promotes innovation and inculcate of the spirit of entrepreneurial culture. On the raking, item 2 ranked first, followed by item 1 as second, item 3 as third, item 4 as fourth and item 5 as fifth. Finally, item 2 came first while item 5 came last.

Research Question 2: In what ways does entrepreneurship programme centres implementation strategy enhances university students' job creation plans in Rivers State? 
Table 4.2: Weighted mean, standard deviation and rank order statistics of male and female lecturers on the ways entrepreneurship programme centre implementation strategy enhances university students' job creation plans in Rivers State

\begin{tabular}{|c|c|c|c|c|c|c|c|c|}
\hline S/No & Items & $\begin{array}{c}\begin{array}{c}\text { Male } \\
\text { teachers }\end{array} \\
\frac{\overline{\bar{x}}_{1}}{}\end{array}$ & $\mathrm{SD}_{1}$ & $\begin{array}{c}\begin{array}{c}\text { Female } \\
\text { lecturers }\end{array} \\
\frac{\overline{\bar{x}}_{2}}{}\end{array}$ & $\mathrm{SD}_{2}$ & $\begin{array}{c}\text { Mean } \\
\text { set }\end{array}$ & $\begin{array}{l}\text { Rank } \\
\text { order }\end{array}$ & Remark \\
\hline 6. & $\begin{array}{l}\text { Teaching entrepreneurship } \\
\text { subjects only }\end{array}$ & 2.47 & 0.96 & 2.35 & 0.96 & 2.41 & $5^{\text {th }}$ & Disagreed \\
\hline 7. & $\begin{array}{l}\text { Developing capacity of } \\
\text { university students }\end{array}$ & 2.51 & 0.89 & 2.49 & 0.96 & 2.50 & $4^{\text {th }}$ & Agreed \\
\hline 8. & $\begin{array}{l}\text { Assisting university students } \\
\text { to start new business }\end{array}$ & 2.51 & 0.92 & 2.59 & 0.95 & 2.55 & $3^{\text {rd }}$ & Agreed \\
\hline 9. & $\begin{array}{l}\text { Training of university students } \\
\text { for job creation plans }\end{array}$ & 2.69 & 0.88 & 2.67 & 0.89 & 2.76 & $2^{\text {nd }}$ & Agreed \\
\hline 10. & $\begin{array}{l}\text { Engaging university students } \\
\text { for research work }\end{array}$ & 3.37 & 1.19 & 3.17 & 0.86 & 3.27 & $1^{\text {st }}$ & Agreed \\
\hline & \multirow{2}{*}{ Grand mean } & 13.55 & 4.84 & 13.27 & 4.62 & 13.49 & & \\
\hline & & 2.71 & 0.97 & 2.65 & 0.92 & 2.70 & & \\
\hline
\end{tabular}

Source: Survey Data (2020).

Data in table 4.2 showed that items $(7$ - 10) had weighted mean scores above the criterion mean of 2.50 and were adjudged as the ways entrepreneurship programme centres implementation strategy enhances university students' job creation plans in Rivers State. While item 6 was rejected because it had mean score that is lower than the criterion mean of 2.50. In summary, with an aggregate weighted mean of 2.70 which is above the criterion mean of 2.50, the respondents agreed that the ways entrepreneurship programme centre implementation strategy enhances university students job creation plans in Rivers State include: developing capacity of university students, assisting university students to start new business, training university students for job creation plans, and engaging university students for research work. On the ranking, item 10 ranked first, followed by item 9 as second, item 8 as third, item 7 as fourth and 6 as fifth. Finally, item 10 came first while item 6 came last.

\subsection{Test of Hypotheses}

The null hypotheses formulated for the study were tested by the means of z-test analysis, which is a test of difference of mean.

$\mathbf{H}_{\mathrm{ol}}$ : There is no significant difference between the mean score of male and female lecturers on the ways functional curriculum implementation strategy enhances university students' job creation plans in River State.

Table 4.3: Summary of z-test analysis on the mean scores of male and female lectures on the ways functional curriculum implementation strategy enhances university students' job creation plans in Rivers State

\begin{tabular}{|l|c|c|c|c|c|c|c|c|}
\hline Category & $\mathbf{N}$ & $\bar{x}$ & SD & Level of sig & Df & z-cal & z-crit & Decision \\
\cline { 1 - 5 } Male lecturers & 163 & 2.66 & 1.07 & \multirow{2}{*}{0.05} & 257 & -0.72 & +1.96 & \multirow{2}{*}{ Accepted } \\
\hline Female lecturers & 96 & 2.62 & 1.05 & & & &
\end{tabular}


Table 4.3 showed that male lecturers have mean and standard deviation of 2.62 and 1.05 respectively. With a degree of freedom of 257 at an alpha level of 0.05 , the calculated zvalue of 0.72 is lesser than the critical $z$-value of +1.96 . Therefore, the null hypothesis was accepted. By implications, there is no significant difference between the mean scores of male and female lecturers on the ways functional curriculum implementation strategy enhances university students' job creation plans in Rivers State.

$\mathbf{H}_{02}$ : There is no significant difference between the mean scores of male and female lecturers on the ways entrepreneurship programme centre implementation strategy enhances university students job creation plans in Rivers State.

Table 4.4: Summary of z-test analysis on the mean scores of male and female lecturers on the ways entrepreneurship programme centre implementation strategy enhances university students' job creation plans in Rivers State

\begin{tabular}{|l|c|c|c|c|c|c|c|c|}
\hline Category & $\mathbf{N}$ & $\bar{x}$ & SD & Level of sig & Df & z-cal & z-crit & Decision \\
\hline Male lecturers & 163 & 2.71 & 0.97 & \multirow{2}{*}{0.05} & 257 & -0.48 & +1.960 & \multirow{2}{*}{ Accepted } \\
\cline { 1 - 5 } Female lecturers & 96 & 2.65 & 0.92 & & & & \\
\hline
\end{tabular}

Table 4.4 showed that male lecturers had mean and standard deviation scores of 22.71 and 0.97 while female lecturers had mean and standard deviation scores of 2.65 and 0.92 respectively. With a degree of freedom of 257 at an alpha level of 0.05 , the calculated zvalue of -0.48 is lesser than the critical $z$-value of +1.960 . By implications, there is no significant difference between the mean scores of male and female lecturers on the ways entrepreneurship programme centre implementation strategy enhances university students job creation plans in Rivers State.

\section{Discussion of Findings}

It was generally accepted that provision of practical skills for job creation, provision of functional knowledge for self-reliance, development of eco-system that promotes innovation and inculcation of the spirit of entrepreneurial culture are the ways functional curriculum implementation strategy enhances university students job creation plans in Rivers State. This finding agreed with Teshome (2014) who argued that modem day universities are now under pressure to produce graduates with the ability to take advantage of opportunities and come up with their own job creation plans as a means of mediating the challenge of unemployment. The above findings is further corroborated by European Union (2006) who asserted that functional curriculum has a vital role in developing eco-system that promotes innovation.

The result of the analysis signified that developing capacity of university students, assisting university students to start new business, training of university students for job creation plans and engaging university students for research work are the ways entrepreneurship programme centre implementation strategy enhances university students job creation plans in Rivers State. This is supported by European Commission (2006) who opined that training of entrepreneurs and conducting researches and 
consultancies by small business development centres in universities are considered inevitable for patenting entrepreneurial, industrial and economic growth in Rivers State.

\section{Conclusion}

Based on the findings of this study, it was concluded that provision of practical skills for job creation, provision of functional knowledge for self-reliance, inculcation of the spirit of entrepreneurial culture, training of university students for job creation plans and engaging university students for research work are the ways functional curriculum and entrepreneurship programme centre implementation strategies enhances university students job creation plans in Rivers State.

\subsection{Recommendations}

Based on the findings and as well as the conclusion of the study, the following recommendations were offered for implementation.

- Government and other stakeholders in education should establish entrepreneurship programme centres where students should exhibit financial skills, business skills, public relations skills and competencies to start a business.

- Also, this paper further recommends curriculum review, sensitization, advocacy and mobilization of support for entrepreneurship education by the stake holders.

- Finally, government should introduce entrepreneurship education at both secondary and university education to enable students acquire skills and business temper of minds.

\section{Conflict of Interest Statement}

The authors declare no conflicts of interests.

\section{About the Author}

Dr. Ifeanyichukwu Emmanuel Nwabueze, MNAEAP, MNARD, MTRCN, Faculty of Education, Educational Management, University of Port Harcourt, Nigeria. Dr. I. E. Nwabueze took a first Degree, B.Ed, in Business Education from the University of Ibadan (1999), M.Ed. and Ph.D. in Educational Management (Administration) from the University of Port Harcourt (2014 and 2018) respectively. He took up appointment as a Confidential Secretary III in the University in 2011 and in 2016 converted to a lecturer. Appointments: SERVICOM Customer and Complaints Desk Officer, Member Academic and Students Results Committee, Departmental Result Upload Officer, Technical Officer Journal of Education in Developing Areas (JEDA) and Faculty Representative on Predegree/Certificate Programme. 


\section{References}

Abraham, N. M. (2011). Management of education for sustainable national development in Nigeria. A Book of Readings in Honour of Professor John Okpako Enaohwo. Choba: University of Port Harcourt.

Amuseghamn, A. S. \& Tayo, O. O. (2009). Spinning off an entrepreneurship culture among Nigerian university students: prospects and challenges. African Journal of Business Management Vol 3. (3). Pp 080-088.

Basu, A. \& Virick, M. (2008). Assessing entrepreneurial intentions amongst students: A comparative study: Retrieved from http://works.bepress.com/anuradha-ba su/12/ (Accessed: December 10, 2015).

European Commission (2006). Promoting entrepreneurship in schools and universities. EUR Lex 33. Implementing the Community Lisbon Programme: Fostering entrepreneurial mindsets through education and learning. Retrieved, September 10, 2016 from http://eur- lex.european.eu/legal-ontent/EN/TXT/?Uri=URISERN:ne611.

Farhangmerh, M., Goncalves, P., \& Sarmento, M. (2016). Predicting entrepreneurial motivation among university students: The role of entrepreneurship education. Education and Training. 58 (7/8). 861 -881.

Gerba, D. T. (2012). Impact of entrepreneurship education on entrepreneurial intentions of business and engineering students in Ethiopia. African Journal of Economic and Management Studies, 3(2), 258 - 277.

Hill, F. \& Leitch, C. (2003). Entrepreneurship education and training. Ashgate: Aldershot.

Iqbal, A., Nelhen, Y. \& Kokash, H. (2012). Readiness of the university students towards entrepreneurship in Saudi private university: An exploratory study., European Scientific Journal, 8 (15), 109-131.

Johnson, P. E. (2011). Structural research: Quantitative and qualitative approaches. Boston: Alyn and Bacon.

Mbah, O. (2008). Entrepreneurship: Theory process innovation and value delivery. Awka, De - Emeralds Publishing Co.

Munyaniva, T. \& Mutsau, M. (2015). An analysis of entrepreneurship curriculum content: A case study of the university of Zimbabwe faculty of commerce. European Journal of Business and Management, 7 (20), 198 - 204.

Olagun, Y. A. (2004). Entrepreneurship and small business enterprise in Nigeria. Ibadan: University Press Pic.

Teshome, T. (2014). Attitudes of private higher education students towards entrepreneurship: A case of distance learners in Wolatasodo and Hossana Towns, middle, East Journal of Scientific Research, 19 (2), 277 - 285. 
Nwabueze, Ifeanyichukwu Emmanuel; Anyanwu, Jerome

ENTREPRENEURSHIP IMPLEMENTATION STRATEGIES AND UNIVERSITY

STUDENTS' JOB CREATION PLANS IN RIVERS STATE, NIGERIA

Creative Commons licensing terms

Author(s) will retain the copyright of their published articles agreeing that a Creative Commons Attribution 4.0 International License (CC BY 4.0) terms will be applied to their work. Under the terms of this license, no permission is required from the author(s) or publisher for members of the community to copy, distribute, transmit or adapt the article content, providing a proper, prominent and unambiguous attribution to the authors in a manner that makes clear that the materials are being reused under permission of a Creative Commons License. Views, opinions and conclusions expressed in this research article are views, opinions and conclusions of the author(s). Open Access Publishing Group and European Journal of Education Studies shall not be responsible or answerable for any loss, damage or liability caused in relation to/arising out of conflicts of interest, copyright violations and inappropriate or inaccurate use of any kind content related or integrated into the research work. All the published works are meeting the Open Access Publishing requirements and can be freely accessed, shared, modified, distributed and used in educational, commercial and non-commercial purposes under a Creative Commons Attribution 4.0 International License (CC BY 4.0). 